\title{
The technology of preparing green coating by conducting micro-arc oxidation on AZ91D magnesium alloy
}

\author{
Sheng Wang*, Pengcheng Liu \\ Lanzhou University of Technology, State key Laboratory of Gansu Advanced Non-ferrous Metal Materials, Lanzhou \\ 730050, China \\ Lanzhou University of Technology, Key Laboratory of Non-ferrous Metal Alloys, The Ministry of Education, Lanzhou \\ 730050, China \\ "Corresponding author: e-mail: wangsheng@lut.cn
}

\begin{abstract}
Micro-arc oxidation was applied to AZ91D magnesium alloy by taking $\mathrm{K}_{2} \mathrm{Cr}_{2} \mathrm{O}_{7}$ as the colouring salt in the silicate system. It was shown that the green coating obtained through performing micro-arc oxidation on magnesium alloy consisted of $\mathrm{Mg}, \mathrm{Mg}_{2} \mathrm{SiO}_{4}, \mathrm{MgO}$, and $\mathrm{MgCr}_{2} \mathrm{O}_{4}$ based on analysis of X-ray diffraction (XRD), and scanning electron microscopy (SEM). Among which, $\mathrm{MgCr}_{2} \mathrm{O}_{4}$ was the colouring salt; there were something in the lamellar, pit, and convex forms found on the surface of the coating. The coating consisted of a porous, and a compact, layer from the outside to the inside. As demonstrated, the colour of the coating depended on the $\mathrm{K}_{2} \mathrm{Cr}_{2} \mathrm{O}_{7}$ concentration: it became gradually deeper with the addition of $\mathrm{K}_{2} \mathrm{Cr}_{2} \mathrm{O}_{7}$ and the increasing micro-arc oxidation time. The corrosion resistance and hardness of the green coating were greater than that of the matrix.
\end{abstract}

Keywords: magnesium alloy, micro-arc oxidation, coating.

\section{INTRODUCTION}

Due to poor wear and corrosion resistance on the surface, the application of magnesium alloy has been limited. Surface treatment technologies for magnesium alloy mainly include chemical transformation ${ }^{1}$, anodic oxidation $^{2,3}$, plasma spraying ${ }^{4}$, organic coatings ${ }^{5,6}, \mathrm{co}-$ ating processes ${ }^{7}$, micro-arc oxidation ${ }^{8}$, etc. Among which, micro-arc oxidation is a surface technology which can produce a coating on the in situ surface of the magnesium alloy. The coating produced shows the following functions: corrosion resistance, decoration, electromagnetic shielding, and electrical insulation. The performance and life-span of the coating are thus improved significantly. Such technology has been successfully applied in industries such as petroleum, textile, aerospace, weapons, ship-building, etc. However, traditional micro-arc oxidation techniques can only generate white coating, which are unable to cover die-casting marks on most magnesium alloy surfaces. Their further applications are limited to special areas due to the monotonous colour thereof. As a result, research on multi-colour surface technologies for conducting micro-arc oxidation on magnesium alloy has already become a research focus. According to studies on white coating, ${ }^{\mathbf{1 0}}$, the ions in the electrolyte are essential components when constructing the coating. That is to say, the phase composition of the micro-arc oxidation coating on the magnesium alloy can be adjusted by changing the components or the concentration of the electrolyte. Thus, oxide coating with the required constituents can be obtained. Furthermore, by adding the colouring salt, the coating is endowed with multiple colours such as pastels, silver-gray, blue, pale-green, and so on, as well as with certain special functions. Wang prepared a blue coating with $\mathrm{CoSO}_{4}$ as the colouring salt, in which cobalt oxide plays a decisive role in the coating colour ${ }^{11}$; Chen X M made a yellow coating with potassium permanganate as the colouring salt, where $\mathrm{Mg}_{6} \mathrm{MnO}_{8}$ is essential in formulating the coating colour $^{12}$; similarly, Chen T H prepared a yellow coating with potassium permanganate as the colouring salt, in which
$\mathrm{Mn}_{2} \mathrm{O}_{3}$ plays an essential role in the coating colour ${ }^{13}$. As seen above, the effect of the colouring salt lies in that it makes the colouring ionic compounds enter and colour the coating under the influences of its electroand physical, chemical properties. Besides, the colour of the coating is influenced by factors including type and dose of colouring salt, technological conditions in the micro-arc oxidation process, etc. This research aimed to reveal the relationships among the concentrations of colouring salt and stabiliser in the electrolyte and the selection of the electrical parameters in the micro-arc oxidation process, and the colour and structure of the final coating. Research shows that $\mathrm{MgCr}_{2} \mathrm{O}_{4}$ was the coloring salt. The coating was composed of a porous layer and a compact layer. The hardness and corrosion resistance were greatly improved compared with the matrix. The optimal process conditions refer to react with $14.0 \mathrm{~g} / \mathrm{L}$ of $\mathrm{Na}_{2} \mathrm{SiO}_{3}, 10.0 \mathrm{~g} / \mathrm{L}$ of KF, $6.0 \mathrm{~g} / \mathrm{L}$ of $\mathrm{NaOH}, 2.0 \mathrm{~g} / \mathrm{L}$ of $\mathrm{K}_{2} \mathrm{Cr}_{2} \mathrm{O}_{7}, 2.5 \mathrm{~g} / \mathrm{L}$ of sodium citrate, at a current density of $2.0 \mathrm{~A} / \mathrm{dm}^{2}$ and a duty ratio of $20 \%$ for $25 \mathrm{~min}$.

\section{EXPERIMENTAL SECTION}

An MA-300 bipolar pulsed power supply for process control during micro-arc oxidation, developed by Lanzhou University of Technology, was used. The voltage of the power supply was in the range of $0 \sim 750 \mathrm{~V}$, the current ranged from 0 to $15 \mathrm{~A}$, and the pulse frequency varied from 100 to $1000 \mathrm{~Hz}$. The devices used in the micro-arc oxidation process included the special power supply, an experimental slot, the mixing system, the cooling system, etc. Magnesium alloy AZ91D was adopted as the specimen and was subjected to grinding, polishing, ultrasonic cleaning, and an alkaline cleaning solution bath. Meanwhile, the micro-arc oxidation process was conducted at a constant current. The electrolyte mainly consisted of sodium, potassium fluoride, sodium hydroxide, potassium dichromate sodium citrate, and ethylene diamine tetraacetic acid (EDTA). Micro-arc oxidation coating was measured by using the DMAX II type X-ray diffraction analyzer. The molecular vibration 
of micro-arc oxidation coating was measured by using the LabRAM HR UV/vis/NIR analyzer. The surface morphology was observed employing the JSM-6700F type SEM and JEM-2010 type TEM. The corrosion potential and the micro-hardness were measured utilizing the electrochemical workstation and the MC010-HVS-1000 type micro-hardness tester, respectively. The thickness was measured utilizing the TT260 type digital thickness gauge by measuring ten points on the surface of each sample and then calculating the weighted average value.

\section{RESULTS AND DISCUSSION}

Under the optimum conditions, the XRD spectra of the prepared green coating are shown in Figure 1. Figure 1 shows that the coloured coating was mainly constituted by the matrix- $\mathrm{Mg}, \mathrm{Mg}_{2} \mathrm{SiO}_{4}$ in cubic structures, $\mathrm{MgO}$, and $\mathrm{MgCr}_{2} \mathrm{O}_{4}$ in spinel structures. Among these components, $\mathrm{Mg}_{2} \mathrm{SiO}_{4}$ and $\mathrm{MgO}$ were white, while $\mathrm{MgCr}_{2} \mathrm{O}_{4}$ was composed of the $\mathrm{MgO}$ and $\mathrm{Cr}_{2} \mathrm{O}_{3}$, and was thus a green crystal with high hardness. Therefore, the colour of the green coating actually resulted from the $\mathrm{Cr}_{2} \mathrm{O}_{3}$ in $\mathrm{MgCr}_{2} \mathrm{O}_{4}$. That is to say, as the $\mathrm{MgCr}_{2} \mathrm{O}_{4}$ content increased in the oxide coating, the colour of the oxide coating was expected to become deeper. The corrosion current was $39.8 \mu \mathrm{A} / \mathrm{cm}^{2}\left(199.5 \mu \mathrm{A} / \mathrm{cm}^{2}\right.$ before micro-arc oxidation) and the micro-hardness of the colourised sample was $490 \mathrm{HV}$ ( $80 \mathrm{HV}$ before micro-arc oxidation). The results revealed that $\mathrm{MgCr}_{2} \mathrm{O}_{4}$ also played an important role in improving the corrosion resistance and hardness of the coating.

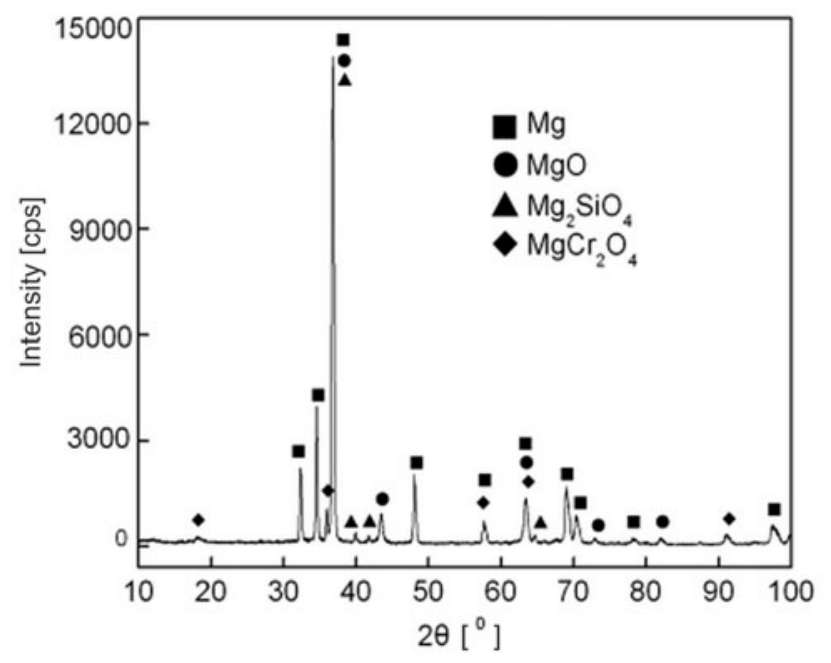

Figure 1. The XRD spectrum of the green coating

Under the optimum conditions, the Raman spectra of the prepared green coating are shown in Figure 2. Figure 2 shows that the vibration peak generated nearby the point $904 \mathrm{~cm}^{-1}$ was caused by the $\mathrm{MgCr}_{2} \mathrm{O}_{4}$. Meanwhile, the vibration peaks generated nearby 1288 $\mathrm{cm}^{-1}$ and $1480 \mathrm{~cm}^{-1}$ attributed to the $\mathrm{Mg}_{2} \mathrm{SiO}_{4}$. That at $1288 \mathrm{~cm}^{-1}$ belonged to the symmetric stretching vibration peak of $\mathrm{Si}-\mathrm{O}$ in the silicon oxygen tetrahedral $\left[\mathrm{SiO}_{4}\right]^{4-}$. As for the vibration peak at $1480 \mathrm{~cm}^{-1}$, it belonged to the asymmetric stretching vibration peak of $\mathrm{Si}-\mathrm{O}$ in the silicon oxygen tetrahedral $\left[\mathrm{SiO}_{4}\right]^{4-}$. No other silicate structure peaks were found. The vibration peak generated nearby the point $1600 \mathrm{~cm}^{-1}$ was caused by the $\mathrm{MgO}$. The vibration peak generated nearby the point $2580 \mathrm{~cm}^{-1}$ was caused by the $\operatorname{Mg}(\mathrm{OH})_{2}{ }^{14,15}$.

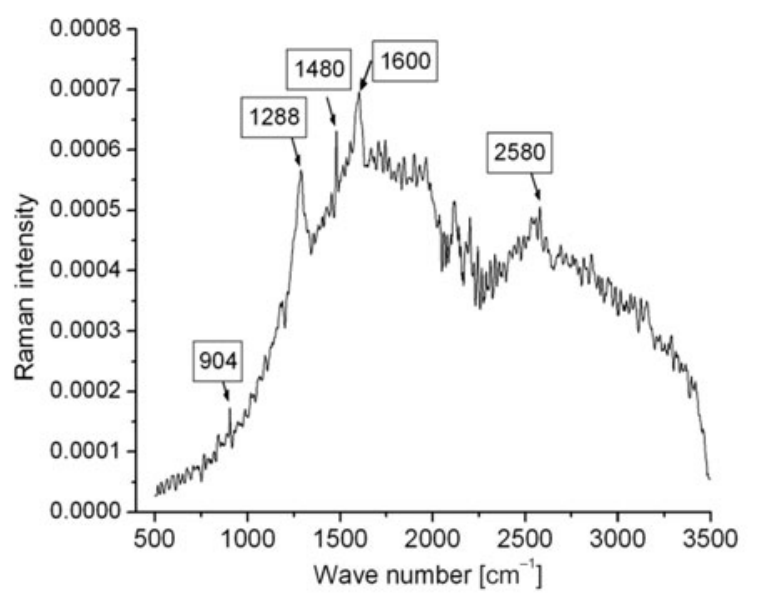

Figure 2. Raman spectra analysis of the green coating

Under the optimum conditions, the green coating was prepared, and the TEM and SEM images are shown in Figures 3 and 4, respectively. As seen in Figure 3, the coating surface had a laminar structure; the cavities on the lamellar layer were channels for the reaction between the electrolyte and matrix, and also the channels for the ejection of the molten compounds. The lamella, pit, and protuberance were formed by the solidification of the ejected molten compounds containing magnesium, silicon, and chromium oxide during micro-arc oxidation. The molten compounds were the product of magnesium alloy and electrolyte under the action of micro-arc oxidation. The maximum pore size was about $70 \mu \mathrm{m}$. As seen in Figure 4, the coating was composed of a porous layer and a compact layer from the outside to the inside. The porous layer could prevent the molten compounds from entering into solution with the internal discharge from the compact layer. Meanwhile, the external surface of the porous layer was able to maintain a balance between the formation of the coating and dissolution in the solution, which prevented the porous layer from becoming thicker. The fundamental reason for its performance being superior was because the coating was combined closely with the matrix and was unlikely to spall off since it grew on the matrix itself. The chemical components of the EDS-scanned area of the green coating are shown in Table 1: there was a $\mathrm{Cr}$ content of $0.92 \%$ on the surface of the coating. By using XRD, it was further shown that $\mathrm{MgCr}_{2} \mathrm{O}_{4}$ was successfully generated on the surface of the coating.

An experiment was conducted to investigate the influence of the $\mathrm{K}_{2} \mathrm{Cr}_{2} \mathrm{O}_{7}$, and sodium citrate, doses on the thickness and colour of the coating. As seen in Figure 5, as the $\mathrm{K}_{2} \mathrm{Cr}_{2} \mathrm{O}_{7}$ dose increased, the coating thickness gradually increased, and its colour turned from white, to pale-green, to green. When the $\mathrm{K}_{2} \mathrm{Cr}_{2} \mathrm{O}_{7}$ dose reached 2.0 $\mathrm{g} / \mathrm{L}$, the coating turned green, and thickness and colour of the coating changed slightly as dose kept increasing. In addition, high-concentrations of $\mathrm{K}_{2} \mathrm{Cr}_{2} \mathrm{O}_{7}$ resulted in a significant increase in the partial breakdown voltage and arcing voltage, which were expected to produce 
Table 1. Composition of the green coating (EDS data)

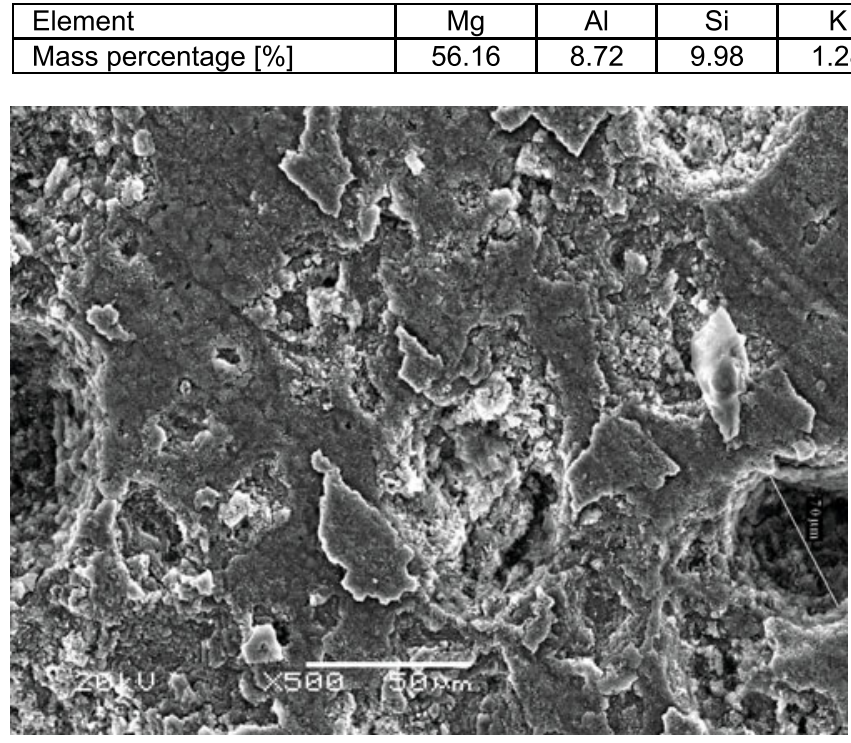

Figure 3. TEM image of the green coating

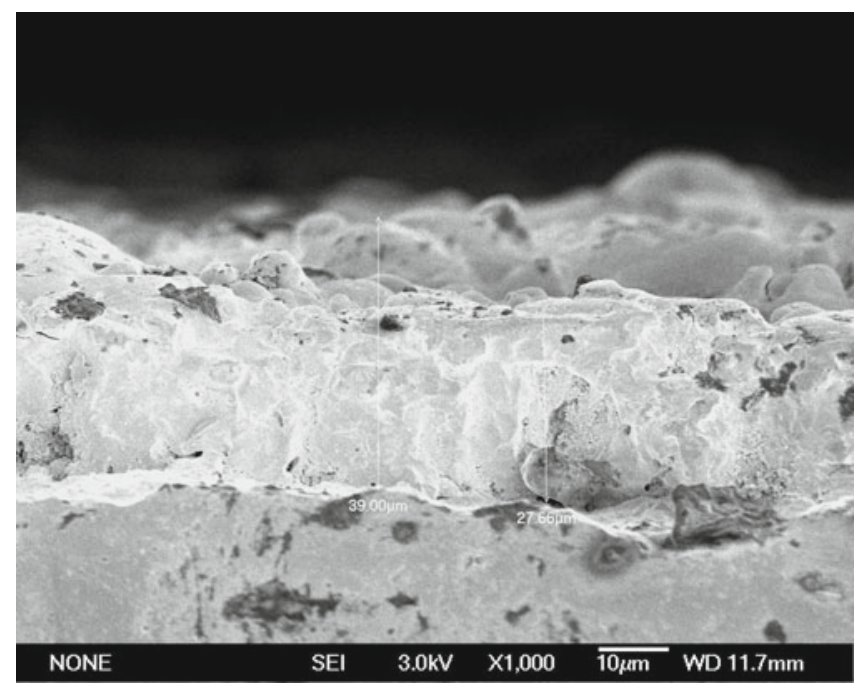

Figure 4. SEM image of the green coating

large amounts of cavities and thus lead to a poor-quality coating surface. From an overall perspective, the optimal $\mathrm{K}_{2} \mathrm{Cr}_{2} \mathrm{O}_{7}$ dose was $2.0 \mathrm{~g} / \mathrm{L}$. Meanwhile, as the stabiliser, sodium citrate could make the formation speed of the coating greater than its rate of growth. This helped generate coating with a more compact structure. As the sodium citrate dose was increased, the thickness of the coating also increased slightly: when the sodium citrate concentration was $2.5 \mathrm{~g} / \mathrm{L}$, the coating exhibited it optimum quality. Therefore, the sodium citrate dose was required to be $2.5 \mathrm{~g} / \mathrm{L}$.

As shown experimentally, the $\mathrm{K}_{2} \mathrm{Cr}_{2} \mathrm{O}_{7}$ dose exerted a significant influence on the arcing voltage. As shown in Figure 6, as $\mathrm{K}_{2} \mathrm{Cr}_{2} \mathrm{O}_{7}$ concentration increased, the arcing voltage needed for macro-arc oxidation increased. At a dose of $3.0 \mathrm{~g} / \mathrm{L}$, the arcing voltage reached $359 \mathrm{~V}$. Meanwhile, transient energy generated in the micro-plasma tended to be absorbed by the surrounding solution, thus leading to a high temperature in the electrolyte, which was not beneficial for generating the best coating. The arcing voltage kept increasing, therefore, the rate of growth of the coating exceeded its rate of formation. Meanwhile, the area of the arc points generated on the surface of

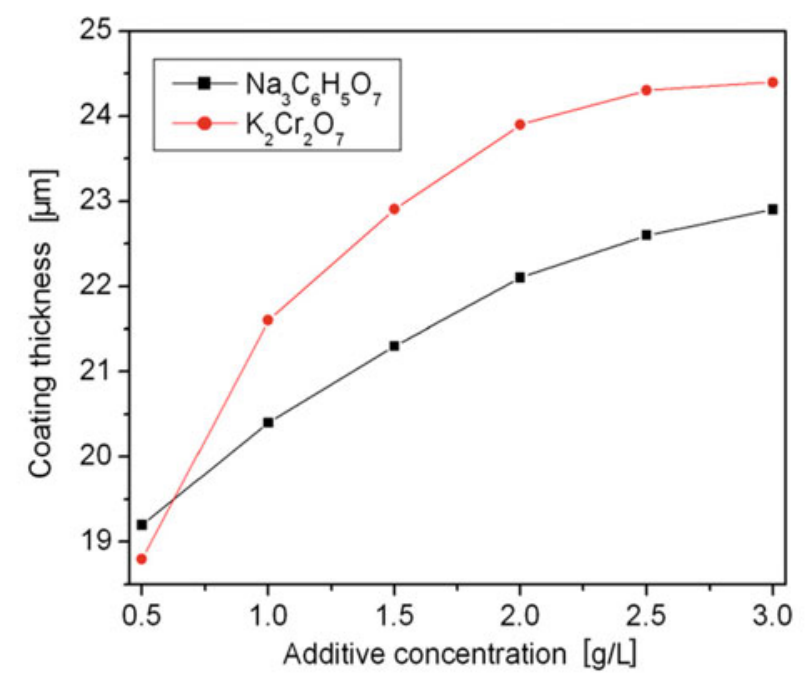

Figure 5. Relationships between the concentrations of potassium dichromate and sodium citrate, and the thickness of the coating

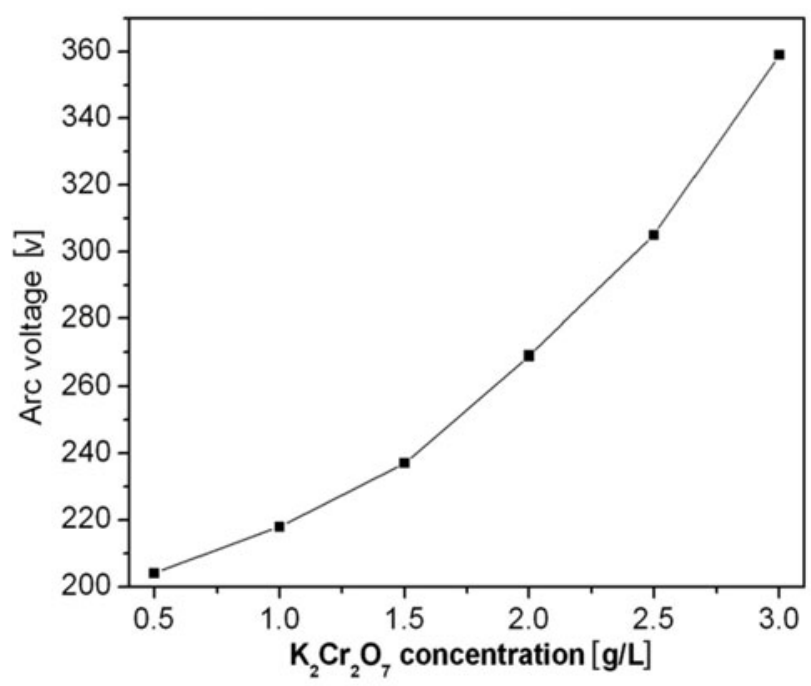

Figure 6. Relationship between the $\mathrm{K}_{2} \mathrm{Cr}_{2} \mathrm{O}_{7}$ dose and the arcing voltage

the specimen increased under a greater arcing voltage, therefore the larger, more frequent, arc points were likely to break down the coating generated. As a result, the coating had large cavities on it, a coarse surface, and an inconsistent colour. According to the colouring effect of $\mathrm{K}_{2} \mathrm{Cr}_{2} \mathrm{O}_{7}$, the $\mathrm{K}_{2} \mathrm{Cr}_{2} \mathrm{O}_{7}$ dose was $2.0 \mathrm{~g} / \mathrm{L}$.

The relationship between the current density and the thickness of the coating is shown in Figure 7: as the current density increased, the coating thickness also increased. As the current density kept increasing, the energy needed to be enhanced so as to improve the transient temperature regime in the micro-plasma. As a consequence, more solution ions could participate in the reaction within a cycle of the formation of discharging channel. Furthermore, the growth rate of the coating accelerated in the presence of a strong current, and the thickness of the coating was greater in the same time. However, when the current density was high enough, 
the number of sparks per unit area decreased while its strength increased. The heat generated was not able to be dissipated immediately, which leads to local overheating. As a result, the coating that was previously generated was damaged, or the surface of the coating became coarser due to the increased micro-plasma energy. Therefore, the optimum current density in these experiments was set to $2.0 \mathrm{~A} / \mathrm{dm}^{2}$.

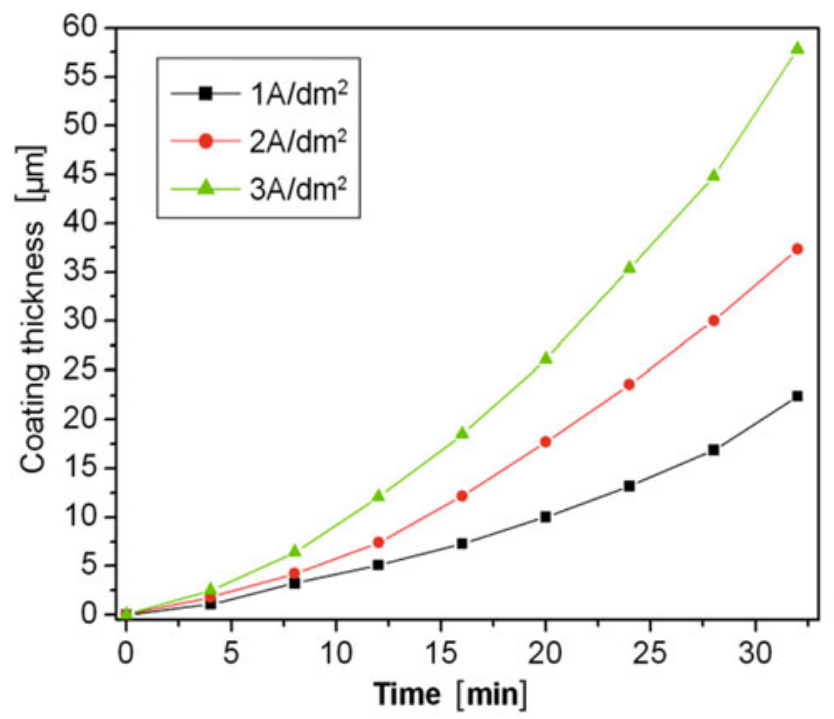

Figure 7. Relationship between current density and thickness of the coating

The effect of a positive duty ratio on the thickness of the coating is shown in Figure 8: as the positive duty ratio increased, thickness of the coating also rose gradually. However, in comparison with the current density, the growth rate of the coating was slower in the same time. With the increase in the duty ratio, the density of the single pulse discharge energy, and discharging point, increased accordingly. Strong discharge was then found in some areas. The melting/solidification volume within the micro-arc of the material increased, so did the increasing rate of the coating thickness. On the contrary, the discharging energy of the positive pulse and formation rate of the coating were low in the case of a low duty ratio. In this case, single pulses presented short durations

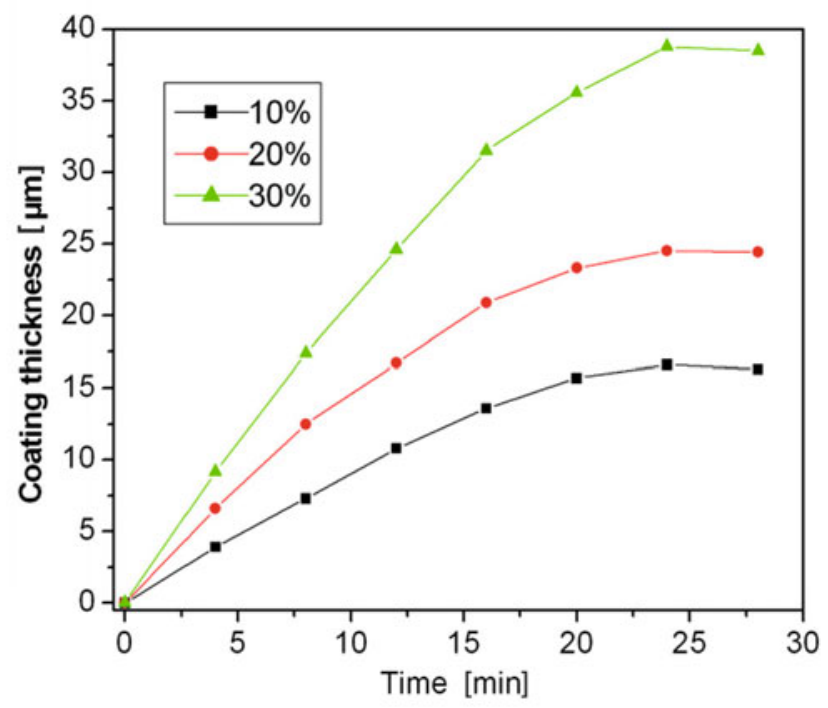

Figure 8. Relationship between duty ratio and thickness of the coating and long break time, and discharged many times with large pulse energy. As a result, the coating obtained was thin, and had a low corrosion resistance. When the duty ratio was kept within a reasonable range (current density parameters are mainly within the range of $0.2 \sim 20 \mathrm{~A} / \mathrm{dm}^{2}$, but the low current density process has a higher industrial prospect), the surface of the coating was shown to be smooth, uniform, and compact, with a better corrosion resistance, and a high hardness. Therefore, the $20 \%$ duty ratio was demonstrated to be optimal.

A $5 \% \mathrm{NaCl}$ solution, with a $\mathrm{pH}$ of 7 , was used as the etching solution for this anti-corrosion testing. After soaking the green ceramic film prepared by micro-arc oxidation of AZ91D magnesium alloy under the optimum conditions for 48 hours, the corrosion rate calculated using the mass loss method was $1.02 \%$ : this showed that the AZ91D magnesium alloy had a preferable corrosion resistance after its colouration by micro-arc oxidation. The corrosion potential of the green ceramic film prepared through micro-arc oxidation tested in an electrochemical workstation, was $-1.428 \mathrm{~V}(-1.485 \mathrm{~V}$ before micro-arc oxidation), and the corrosion current was $39.8 \mu \mathrm{A} / \mathrm{cm}^{2}$ $\left(199.5 \mu \mathrm{A} / \mathrm{cm}^{2}\right.$ before micro-arc oxidation). This demonstrated that the AZ9ID magnesium alloy had a preferable corrosion resistance after micro-arc oxidation. The micro-hardness of the colourised sample was $490 \mathrm{HV}$ ( $80 \mathrm{HV}$ before micro-arc oxidation), which revealed that the hardness of the AZ91D magnesium alloy improved significantly after micro-arc oxidation.

\section{CONCLUSIONS}

1. By using $\mathrm{K}_{2} \mathrm{Cr}_{2} \mathrm{O}_{7}$ as the colouring salt, the prepared green coating consisted of $\mathrm{Mg}, \mathrm{Mg}_{2} \mathrm{SiO}_{4}$, and $\mathrm{MgCr}_{2} \mathrm{O}_{4}$ based on XRD analysis, where $\mathrm{MgCr}_{2} \mathrm{O}_{4}$ was the colouring salt. TEM results showed that, the lamella, pit, and protuberance on the surface of the coating were formed by the solidification of ejected molten compounds. SEM analysis revealed that the coating was composed of a porous layer and a compact layer when viewed from outside to inside.

2. The colour of the coating gradually became deeper as the $\mathrm{K}_{2} \mathrm{Cr}_{2} \mathrm{O}_{7}$ concentration and micro-arc oxidation time increased; meanwhile, as the $\mathrm{K}_{2} \mathrm{Cr}_{2} \mathrm{O}_{7}$ concentration increased, the arcing voltage during micro-arc oxidation also increased in a step-by-step manner, which influenced the micro-arc oxidation process. While preparing the green coating on the magnesium alloy using microarc oxidation, the optimal process conditions included a $\mathrm{K}_{2} \mathrm{Cr}_{2} \mathrm{O}_{7}$ dose of $2.0 \mathrm{~g} / \mathrm{L}$, a sodium citrate dose of 2.5 $\mathrm{g} / \mathrm{L}$, a current density of $2.0 \mathrm{~A} / \mathrm{dm}^{2}$, a duty ratio of $20 \%$, and a processing time of 25 minutes.

3 . The performance test on a green coating prepared by micro-arc oxidation on a magnesium alloy, demonstrated that its corrosion resistance and hardness were enhanced more significantly compared with the matrix.

\section{ACKNOWLEDGEMENT}

The work was supported by State key Laboratory of Gansu Advanced Non-ferrous Metal Materials, Lanzhou University of Technology (SKL07012). 


\section{LITERATURE CITED}

1. Rafieerad, A.R., Ashra, M.R. \& Mahmoodian, R., et al. (2015). Surface characterization and corrosion behavior of calcium phosphate-base composite layer on titanium and its alloys via plasma electrolytic oxidation. Mater. Sci. Eng. C Mater. Biol. Appl. 57(12), 397-413. DOI: 10.1016/j.msec.2015.07.058.

2. Durdu, S., Aylin, A. \& Metin, U. (2011). Characterization and corrosion behavior of ceramic coating on magnesium by micro-arc oxidation. J. Alloy. Compd. 509(6), 8601-8606. DOI: 10.1016/j.jallcom.2011.06.059.

3. Jacques, B. (2014). Oxidizing electrolysis method for obtaining a ceramic coating at the surface of a metal, US, 6808613, 2004-10-26.

4. Yeung, W.K., Reilly, G.C., Matthews, A., et al. (2013). In vitro biological response of plasma electrolytically oxidized and plasma-sprayed hydroxyapatite coatings on Ti-6Al-4V alloy. J. Biomed. Mater. Res. B Appl. Biomater. 101(6), 939-949. DOI: $10.1002 / \mathrm{jbm} . b .32899$.

5. Hornberger, H., Virtanen, S., Boccaccini, A.R. (2012). Biomedical coatings on magnesium alloys - a review, Acta Biomater. 8(7), 244-255. DOI: 10.1016/j.actbio.2012.04.012.

6. Cakmak, E., Tekin, K.C. \& Malayoglu, U., et al. (2010). The effect of substrate composition on the electrochemical and mechanical properties of PEO coatings on Mg alloys. Surf. Coat. Tech. 204(8), 1305-1313. DOI: 10.1016/j.surfcoat.2009.10.012.

7. Srinivasan, P.B., Liang, J. \& Blawe, R.T.C., et al. (2009). Effect of current density on the microstructure and corrosion behaviour of plasma electrolytic oxidation treated AM50 magnesium alloy. Appl. Surf. Sci. 255, 4212-4218. DOI: 10.1016/j. apsusc.2008.11.008.

8. Razavi, M., Fathi, M., Savabi, O. \& Vashaee, D. (2015). In vivo assessments of bioabsorbable AZ91 magnesium implants coated with nanostructured fluoridated hydroxyapatite by MAO/ EPD technique for biomedical applications. Mater. Sci. Eng. C Mater. Biol. Appl. 3, 21-27. DOI: 10.1016/j.msec.2014.11.020.

9. Veys-renaux, D., Rocca, E. \& Martin, J., et al. (2014). Initial stages of AZ91 Mg alloy micro-arc anodizing: growth mechanisms and effect on the corrosion resistance. Electrochim. Acta. 124, 36-45. DOI: 10.1016/j.electacta.2013.08.023.

10. Young, G.K., Seung, N. \& Dong, H.S. (2010). Correlation between $\mathrm{KOH}$ concentration and surface properties of AZ91 magnesium alloy coated by plasma electrolytic oxidation. Surf. Coat. Tech. 205, 2525-2531.

11. Wang, W.B., Xie, F.Q. \& Wu, X.Q., et al. (2011). Preparation of blue micro-arc oxidation coating on magnesium alloy surface and evaluation of its corrosion resistance. Mater. Protect. 8(44), 45-47.

12. Chen, X.M., Luo, C.P. \& Liu, J.W. (2009). Study on the coloring coating by micro-arc oxidation on magnesium alloys. Mater. Rev. 23(14), 535-537. DOI: 10.3321/j.issn:1005$-023 X .2009 . z 2.158$.

13. Chen, T.H., Ma, Y. \& Ma, Y.Z., et al. (2008). Preparing process and proper ties of micro-arc oxidation colouring coating on magnesium alloy. Mater. Heat Treat. 18(9), 54-57. DOI: 10.3969/j.issn.1001-3814.2008.18.018.

14. Ramsey, J.D., Xia, L. \& Kendig, M.W., et al. (2001). Raman spectroscopic analysis of the speciation of dilute chromate solutions. Corros. Sci. 43, 1557-1572. DOI: 10.1016/ S0010-938X(00)00145-1.

15. Cáceres, D., Vergara, I. \& González, R., et al. (2002). Nanoindentation on neutron irradiated $\mathrm{MgO}$ crystals. Nucl. Instrum. Meth. B. 191(1-4); 178 180. 